\title{
A PERSPECTIVA DE MONSTRO NO LIVRO VIAGENS DE JEAN DE MANDEVILLE: OS SERES DISFORMES VIVENTES NO ORIENTE.
}

\author{
Jorge Luiz Voloski ${ }^{1}$, Jaime Estevão dos Reis ${ }^{2}$ \\ ${ }^{1}$ Acadêmico do Curso de História, Universidade Estadual de Maringá - UEM. Pesquisador do Laboratório de Estudos Medievais - LEM. \\ Bolsista PIBIC/CNPq- UEM. jorgeluizvoloski@gmail.com \\ ${ }^{2}$ Doutor, Departamento de História da Universidade Estadual de Maringá- UEM. Coordenador do LEM - Laboratório de Estudos \\ Medievais. E-mail: jaimeestevaoreis@hotmail.com
}

\section{RESUMO}

Escrito em meados do século XIV o livro Viagens de Jean de Mandeville foi um dos mais difundidos em fins da Idade Média. Existem mais 250 manuscritos diferentes em diversas línguas. Para o desenvolvimento da presente pesquisa utilizamos a edição traduzida por Susani Silveira Lemos França. A obra é dividida em duas partes e narra o deslocamento do suposto cavaleiro, Jean de Mandeville, por terras orientais, mesclando o real e o imaginário. Assim, nesta comunicação, buscamos compreender o maravilhoso presente no livro, possuindo como foco, em especial, os monstros com deformidades físicas. Tais seres possuíam diferentes imperfeições, como por exemplo, orelhas que chegam até o joelho, cabeça de cachorro, pés de cavalo, pedra no lugar dos olhos, entre outros. Em sua grande maioria essas gentes são descritas como habitantes de ilhas, entretanto, também aparecem no deserto e no continente. Utilizaremos autores como, por exemplo, Jacques Le Goff (1985), Claude Kappler (1986), Ana Teresa Pollo Mendonça (2007), Miguél Ángel Ladero Quesada (2007), entre outros.

PALAVRAS-CHAVE: Baixa Idade Média; Jean de Mandeville; Maravilhoso; Monstros.

\section{INTRODUÇÃO}

O livro Viagens de Jean de Mandeville foi um dos escritos mais popularizado em fins da Idade Média. Segundo Miguél Ángel Ladero Quesada, a obra foi escrita inicialmente no dialeto franco-normando, sendo concluída até o ano de 13571. Depois de acabada, a obra recebeu, inicialmente, traduções para o inglês e latim, em seguida para outros idiomas. Existem hoje mais de 250 manuscritos em diferentes línguas europeias ${ }^{2}$ (QUESADA, 2007).

Carmem Cuenca divide os manuscritos, legados a atualidade, em dois grupos diferentes: a versão peninsular e a continental baseada na versão anglo-normanda. A principal diferença entre ambas é que a versão quase exclusivamente britânica não apresenta qualquer informação que vincule a história do autor com certo Jean de Bougogne ou com Jean D'Outremeouse, enquanto essas informações aparecem na versão continental (CUENCA, 1986).

Para o desenvolvimento da presente pesquisa utilizamos a versão traduzida e comentada por Susani Silveira Lemos França, a qual, por sua vez, defronta as três edições modernas do manuscrito inglês - editadas por Paul Hamelius, M. C. Seymour e o primeiro volume da edição de Malcolm Letts-, com a segunda edição de Malcolm Letts, além da versão insular, em anglo-normando, preparada por Christiane Deluz, e as três edições de Ana Pinto (FRANÇA, 2017).

\footnotetext{
1 C. W. R. D. Moseley coloca que em alguns manuscritos Jean de Mandeville viajou no ano de 1322 e regressa em 1336 (MOSELEY, 1983).

2 De acordo com Christiane Deluz, o livro de Jean de Mandeville foi escrito no ano de 1356 na cidade de Lieja. Na Inglaterra, o texto chega por volta de 1357, sendo traduzidos de imediato para o anglo-normando. Tradução essa que serve de base para as subsequentes (RUIZ DE TOLEDO, PORTELA, 2006).
} 
A fonte que utilizamos está dividida em duas partes ${ }^{3}$. Na primeira, além do prólogo ${ }^{4}$, o autor apresenta as melhores rotas para o itinerário da Inglaterra até a Terra Santa. Enquanto na segunda, são narrados os locais além de Jerusalém até o Extremo Oriente, mais especificamente, a terra de Preste João. Em ambas as partes abundam as manifestações maravilhosas.

Desta forma, está comunicação tem como objetivo analisar as maravilhas presentes na obra de Jean de Mandeville, focando, em especial, os "monstros". Para tal empreitada, sintetizamos, primeiramente, a concepção que o homem medieval possuía do maravilhoso, visto que, como aponta Jacques Le Goff, o problema fundamental ao estudar as mirabilia em uma sociedade é o vocabulário (LE GOFF, 1985).

Isto posto, compreendemos os monstros, assim como coloca Pablo Castro Hernández, como uma categoria que se desprende do maravilhoso, ou seja, como um componente natural, mas que, por ser diferente, causa admiração, assombro e espanto (CASTRO HERNÁNDEZ, 2005).

Em seguida, por meio de estudos de outros pesquisadores, percebemos que o termo "monstro" possuía utilidade diferente de acordo com o lugar em que estava descrito, ou desenhado. Assim, nesta comunicação, não buscamos compreender o sentido amplo do monstro, nem apresentar uma categorização, mas, ao contrário, procuramos compreender a relação e as transformações dos seres disformes ao longo do livro Viagens de Jean de Mandeville, em especial na tradução de Susani Silveira Lemos França.

Para tal empreitada, partimos da concepção geográfica de Jean de Mandeville, sobretudo, a redondeza da terra. Não deixamos de lado, entretanto, a localização dos monstros, se destacando, neste ponto, três lugares diferentes, o deserto, as ilhas e o continente.

Por fim, é importante destacar que o principal guia para o entendimento de monstro presente nessa comunicação é proposta por Jean de Mandeville, o qual define monstro como "um ser disforme, seja homem, animal, seja qualquer outro ser, por isso se chama monstro" (MANDEVILLE, 2017, p.70-71).

\section{MATERIAIS E MÉTODOS}

Segundo Ana Teresa Pollo Mendonça a palavra mirabilia está ligada, por meio de sua raiz, com a imagem. Sem embargo, o vocábulo não se refere exclusivamente aos fenômenos vistos, ao contrário, carrega significado às coisas observadas pelo interiores oculus, ou seja, os olhos da imaginação. Sobre o termo Miror, raiz latina da locução "maravilha", a autora coloca que carregava, durante a Idade Média, o significado de admiração e surpresa, sobretudo pela novidade (MENDONÇA, 2007).

Jacques Le Goff, assim como MENDONÇA (2007), coloca o maravilhoso como caracterizado pela raridade e espanto, em geral admirativo. $O$ autor também ressalta que, atualmente, tendemos a categorizar as maravilhas,

Contudo, enquanto definimos uma categoria, um tipo de realidade, a Idade Média latina vê um conjunto, uma coleção de seres, fenômenos, objetos, possuindo

\footnotetext{
3 Segundo Vladmir Acosta, "el libro de Mandeville puede dividirse claramente en dos grandes partes, aunque algunas ediciones lo dividen en cinco y pese a que los manuscritos por lo general no hacen ninguna división" (ACOSTA, 1992, p.220).

4 É no prólogo que o autor se identifica como Jean de Mandeville, cavaleiro, nascido na Inglaterra, Saint. Albans, que realiza no ano de 1322, uma viagem além do mar. Outra informação a respeito do autor aparece no fim da obra, aonde, ele coloca o ano de 1356 como seu regresso para a Europa por causa de uma artrite gotosa. Essas informações por séculos foram tidas como verdadeiras, todavia, em meados dos séculos XIX, pesquisadores começaram a duvidar tanto da existência de Jean de Mandeville, quanto do real deslocamento do autor.
} 
todos as características de serem surpreendentes, no sentido forte da expressão, e que podem estar associados quer ao domínio propriamente divino (portanto próximo ao milagre), quer ao domínio natural (sendo a natureza originalmente o produto da criação divina), quer ao domínio mágico, diabólico (portanto, uma ilusão produzida por Satã e seus seguidores sobrenaturais ou humanos) (LE GOFF, 2017, p.121).

Esta comunicação tem como objetivo analisar o maravilhoso em seu domínio natural, mais especificamente, os monstros. Assim, esquivamos do debate proposto por Claude KAPPLER (1986), o qual coloca os demônios e as maravilhas como dois pólos opostos dos monstros, partindo da descrição, por parte de Jean de Mandeville, de um ser disforme, conservado em Constantinopla por ser "uma maravilha".

Estas gentes disformes, de acordo com Mary Del Priori, são representadas em inúmeros lugares diferentes ao longo da Idade Média, como, por exemplo, nas pinturas, esculturas, arquiteturas, bestiários, possuindo funções diferentes em cada caso (DEL PRIORI, 2000). O presente estudo busca analisar os monstros descritos no livro Viagens de Jean de Mandeville, traduzido e organizado por Susani Silveira Lemos França, excluindo, portanto, a pretensão de um diagnóstico detalhado dos monstros presentes em outras versões da obra.

Isso não impede, no entanto, que recorramos a temáticas paralelas, entre elas, a presente na obra de Alixe Bovery, Monstruos y grotescos en los manuscritos medievales (2006). Neste livro o autor afirma que, para os artistas medievais, os monstros não eram apenas usados com o objetivo de moralizar, em contrapartida, podiam também ser divertidos ou descritos na finalidade de causar medo ao leitor (BOVERY, 2006).

Contudo, ao longo da Idade Média, não importava, aos leitores, se os monstros eram descritos para provocar medo, moralizar, ou causar risos, pois, em todos os casos eles eram tidos como existentes. Quando, por exemplo, um viajante rumava até as Índias devia incluir em seus escritos as descrições dos seres prodigiosos porque isso formava o real das terras longínquas (TOVAR, 2006).

Para Victoria Cirlot Valenzuela os monstros eram uma realidade geográfica, ocupavam, desta forma, zonas limites, ou seja, as fronteiras do mundo natural e conhecido. Já em fins da Idade Média, com o aumento dos deslocamentos para o Oriente, alguns viajantes, ao regressarem a Europa, narravam com perplexidade o fato de não encontrarem seres com deformidades físicas, é o caso, por exemplo, do mercador Marco Polo (VALENZUELA, 1990)

Jean de Mandeville, ao contrário dos viajantes reais, apresenta um acoplado das maravilhas existentes no Oriente. Isso ocorre, segundo Susana Morales Hoyos e Sonia Fernández Osorio, porque o suposto cavaleiro não descobre o Oriente assim como outros viajantes, mas o observa com o olhar de outros viajantes. Para as autoras, o livro Viagens de Jean de Mandeville busca uma reformulação do pensamento antigo sobre o Oriente, sobretudo em relação ao outro, o qual, na obra, forma um espelho para o entendimento de si (OSORIO, HOYOS, 2006).

A tentativa de reformular o pensamento em relação ao Oriente é evidente em certas partes, como por exemplo, em momentos que o suposto cavaleiro observa características da fé Cristã na religião dos povos orientais.

O fato de Jean de Mandeville ver de forma diferente outros países tem paralelo com sua rejeição à tradição irracional do maravilhoso que dominava os escritos anteriores (MONSELEY, 2015). Assim, o cavaleiro não apenas descreve os monstros, mas busca uma explicação para tais deformidades, as quais podem surgir tanto por fatores climáticos, quanto pelo cruzamento entre seres humanos e demônios (MANDEVILLE, 2017).

Sem embargo, mesmo sendo prováveis frutos da relação entre demônios e seres humanos os monstros não eram completamente privados da salvação eterna. Em certo 
momento de seu relato o suposto cavaleiro narra à história de um ermitão que encontra um ser disforme no deserto. Este monstro, quase como um homem, todavia possuía dois chifres na testa e metade do corpo em forma de cobra, afirma ser criado por Deus e solicita ao ermitão receber orações (MANDEVILLE, 2017).

Assim, percebemos que suposto cavaleiro se aproxima da concepção de Santo Agostinho de monstro. Segundo Guilherme Jacinto Schneider, Santo Agostinho coloca os monstros como um ensinamento de Deus, aquele que, "pela própria existência tem algo a mostrar, seja sobre o futuro (como um presságio) ou sobre um aspecto divino" (SCHNEIDER, 2015). Jean de Mandeville demonstra, portanto, que todos, inclusive os seres disformes fruto da relação entre demônios e seres humanos, podem obter a salvação divina.

Contudo, a ideia de que "monstro" indica ou ensina algo não era exclusiva de Santo Agostinho, visto que, à própria etimológica da palavra carrega esse significado. Como afirma CASTRO HERNÁNDEZ (2005, p.18),

a palavra monstro deriva do latim monstrum, isto é, monstros, prodígio, maravilha e coisas incríveis, ao que a sua vez deriva monstro, é dizer, mostrar, indicar e sinalar. O monstruoso é um gênero de criaturas que mostra, apresenta e prognostica algo com um significado. São seres que [se] diferem das formas tradicionais da criação o do cânon da normalidade do ser humano, centrando sua essência na deformação ou alteração do corpo e [de] sua natureza ${ }^{5}$.

Em suma, como coloca Almut Höfert, o termo monstro designa animais, humanos e híbridos que fogem da aparência natural e da ordem estabelecida, mas, ao mesmo tempo, ensinam bem como indicam algo. O autor coloca que essas gentes disformes também possuem uma História, pois, sofrem mutações nas descrições ao longo dos séculos (HÖFERT, 2016).

Mary Del Priori observa três momentos diferentes da relação do homem com os monstros ao longo da ldade Média: primeiramente, as gentes disformes são vistas como o que o homem poderia ser; posteriormente, entre os séculos XII-XIII, os monstros adquirem um caráter moralista; por fim, no século XIV, o homem medieval olha-os como punição de Deus. Além do mais, a autora afirma que pouco, ou quase nada, a Idade Média criou de monstros, alterando e adaptando os herdados pela Antiguidade (MARY DEL PRIORI, 2000).

Entre os monstros da Antiguidade presentes na obra de Jean de Mandeville observamos, por exemplo, os pequenos Pigmeus; Ciápodes, ou Esciópodas, os quais, correm muito e possuem apenas um pé; Cinocéfalos, que possuem cabeça de cão; Blêmias, seres sem cabeça e com os olhos nos ombros; Hipópodes, seres humanos com pé de cavalo; Panotios, orelhas tão grande que cobrem o corpo; Gerclitos, ou ciclopes, com um único olho na testa.

\section{RESULTADOS E DISCUSSÕES}

Segundo Miguél Ángel Ladero Quesada o autor do livro Viagens de Jean de Mandeville era um homem de ampla cultura que deixa transparecer, ao longo de seu escrito, rasgos de sua personalidade bem como de suas opiniões. Bom cristão, mesmo com críticas direcionadas aos clérigos, o suposto cavaleiro leva o leitor do conhecido para o desconhecido, mediante um descobrimento do mundo, que carrega dados históricos,

\footnotetext{
5 "La palavra monstruo deriva del latín monstrum, esto es, monstruos, prodígio, maravilla y cosas increíbles, lo que a su vez deviene monstro, es decir, mostrar, indicar y señalar. Lo monstruosos es un género de criaturas que muestra, presentea y pronostica algo con su significado. Son seres, que difieren de las formas tradicionales de la creación o del canon de la 'normalidad del ser humano, centrando su esencia en la degormación o alteración del cuerpo y su caturaleza" (CASTRO HERNÁNDEZ, 2005, p.18).
} 
lendas e mirabilia as quais, se avolumam na medida em que o viajante se distancia da terra natal (LADERO, 2007).

Para Pablo Castro Hernández, o Livro das maravilhas do mundo, também traduzido ao português com o título Viagens de Jean de Mandeville, apresenta uma síntese do conhecimento geográfico, antropológico, histórico, científico e enciclopédico de fins da Idade Média. "Em certa medida, podemos notar como sua narração constitui um conjunto de notícias e um repertório de conhecimento que estabelecem uma representação da imago mundi de seu tempo"6 ( HERNANDEZ, p.189, 2013).

A imagem do mundo, no escrito de Jean de Mandeville, é representada de forma redonda. Como justificativa para tal primazia o autor coloca a impossibilidade de ver a principal estrela que serve de guia para os marinheiros europeus, chamada de Tramontana, em determinada região do Oriente, e o surgimento de uma nova estrela, Antártica, a qual pode ser vista a partir das terras além da Líbia. Assim, o suposto cavaleiro assegura que "um homem poderia rodear toda a terra do mundo, tanto por cima como por baixo, e regressar a seu país, se tivesse companhia e embarcações" (MANDEVILLE, 2017).

Para alguns pesquisadores, entre eles, por exemplo, George H. T. Kimble em seu livro A geografia na Idade Média (2005), Jean de Mandeville descreve as antípodas ao colocar que,

\begin{abstract}
os que vivem sob a estrela Antártica estão pé contra pé com aqueles que vivem sob a estrela Tramontana, assim como nós e os que vivem no lugar oposto ao nosso estamos pé contra pé. Todas as partes do mar e da Terra têm seu oposto, habitáveis e acessíveis, que as equilibram. E compreendei que, no meu modo de pensar, as terras do preste João, imperador da Índia, acham-se exatamente por baixo de nós. E, se um homem partisse da Escócia ou da Inglaterra para Jerusalém, caminharia sempre para cima, pois, nossa terra está na parte baixa do Ocidente e a terra do preste João, na parte baixa do Oriente, onde é dia quando entre nós é noite. E também, em contrapartida, lá é noite quando entre nós é dia (MANDEVILLE, 2017, p. 171).
\end{abstract}

Sobre as Antípodas Claude Kappler coloca que são gentes que estão ao revés, do outro lado do mundo, no entendimento do homem medieval, estes seres estavam literalmente pregados as suas solas, sendo cada cristão correspondente a outro deles. No país das antípodas tudo acontece ao contrário, enquanto, por exemplo, no Ocidente cristão é dia, lá é noite (KAPPLER, 1986).

As antípodas, que se encontram na terra de Preste João, são formadas por cinco seres disformes diferentes: homens cornudos, de horroroso aspecto, que não falam apenas grunhem; seres grandes como gigantes, 28 a 30 pés de altura que se vestem com peles de animais e preferem comer carne humana; mulheres com pedras preciosas no lugar dos olhos, as quais são cruéis e de má índole, podendo matar um homem apenas com o olhar; seres pequenos como os anões, um pouco maiores que os Pigmeus, que vivem dos odores de uma maçã, além de não serem completamente racionais, antes, simples e bestiais; pessoas inteiramente peludas, exceto no rosto e na palma das mãos.

Outro grupo de monstros se encontra da Líbia até a terra de Preste João, são eles: pessoas com apenas um pé tão grande que quando deitada faz sombra; homens que possuem os testículos pendentes até o meio das pernas por causa do calor; homens e mulheres com cabeça de cachorro que adoram um boi; gigantes horríveis à vista que possui apenas um olho na testa; pessoas feias que não possuem cabeça, com os olhos nos ombros e a boca curvada como a ferradura de um cavalo, situada no meio peito;

\footnotetext{
6 "En certa medida, podemos notar como su narración contituye un conjunto de noticias y un repertorio de conocimientos que establecen una representación de la imago mundi de su tiempo" (CASTRO HERNÁNDEZ, 2013, p. 189).
} 
gentes sem cabeça, com os olhos na parte de trás dos ombros; pessoas com o rosto plano, sem nariz e olhos, somente com dois furos redondos no lugar dos olhos e uma boca plana sem lábio; gentes com o lábio superior muito grande; seres pequenos como anões, mas maiores que os pigmeus, que possuem um orifício redondo no lugar da bora, por esta razão, comem e bebem através de um tipo de cano; gentes com grandes orelhas, que chega até os joelhos; seres com pés de cavalo; pessoas que andam sobre as mãos e os pés, como os animais, e são peludas; gentes que são ao mesmo tempo homem e mulher; pessoas que caminham de joelho e possuem oito dedos em cada pé; seres de pequena estatura, chamados de Pigmeus; Ypotaynes, que são seres metade homem, metade cavalo.

Por fim, da Inglaterra até Jerusalém encontramos apenas uns monstros diferentes, o qual, não foi visto com vida. Jean de Mandeville afirma que, esse ser foi visto por um ermitão no deserto e que a sua cabeça está conservada em Alexandria por ser uma maravilha.

Destes monstros descritos a grande maioria vivia em ilhas, cerca de 17, são os homens que possuem testículo que chegam até a perna; homens e mulheres com cabeça de cão; gigantes com um olho na testa; seres com olho no ombro e sem cabeça; pessoas com os olhos e a boca na parte de trás dos ombros; seres com rosto plano; pessoas com lábio superior grande; seres pequenos como os anões, com um orifício redondo no lugar da boca; pessoas com as orelhas que chegam até os joelhos; pessoas com pé de cavalo; seres que andam sobre os pés e mão; seres que são ao mesmo tempo homem e mulher; pessoas que caminham de joelho, possuem oito dedos em cada pé; gigantes de 28 a 30 pés de altura; mulheres que possuem pérolas nos olhos; pessoas quase anãs, que se alimentam com o cheiro de uma maça; seres completamente peludos.

No deserto, dois monstros diferentes são descritos: o ser com dois chifres pontiagudos na testa, que possui metade do corpo de homem e outra metade de cabra, e os homens selvagens cornudos, que não falam apenas grunhem.

Por fim, no continente, quatro seres diferentes são narrados: Andrômeda, gigante a qual possui uma costela de 40 pés de altura; homem com um pé, grande e que caminha muito rápido; Pigmeus; Ypotaynes, seres metade homem e metade cavalo.

\section{CONSIDERAÇÕES FINAIS}

Em primeiro lugar, devemos destacar que a inclusão dos seres disformes no âmbito das maravilhas fez com que percebêssemos os monstros descritos pelo suposto cavaleiro de forma diferente, ou seja, como parte integrante da natureza, podendo ser, até mesmo, seres humanos. Prova isso o uso do termo "gente", usado para designar tanto as "pessoas" com deformidades físicas, quanto "a gente comum". Importante ressaltar que, quando o autor se refere aos seus leitores os vocábulos usados são diferentes, entre eles, observamos, por exemplo, "cavaleiros", "senhores temporais", "nobres", "homens", "leitores", "ouvintes cristãos".

Em relação a antípodas percebemos cinco monstros diferentes descritos, sendo quatro deles habitantes de ilhas, dos quais dois comem ou matam os humanos, um é pequeno e possui boa aparência além de ser irracional, por último, um é peludo. Já o outro ser disforme, que possuía dois chifres, é descrito como vivente no deserto.

Importante destacar que em outro momento que Jean de Mandeville narra um monstro que possui chifre é na primeira parte, entretanto, o viajante não o viu. Coisa semelhante ocorre com o gigante chamado Andrômeda, descrito anterior a Jerusalém, mas não visto pelo cavaleiro. Ou seja, Jean de Mandeville não descreve nem ser humano com deformidade física, vivo, antes de Jerusalém, em casos extremos, por exemplo, na mulher que se transformou em dragão, temos a mutação em outro ser creditado como real, neste caso o dragão. 
Além do mais, percebemos que os monstros aparecem em sua maioria entre Jerusalém e a Terra de Preste João. A grande maioria habitava ilhas e suas formas variavam alguns com excessos e outros com mutações físicas.

Por fim, vale destacar que, para uma conclusão mais precisa dos seres disformes presentes no livro Viagens de Jean de Mandeville seria necessário um estudo mais detalhado o qual, além de entender por completo o pensamento de Jean de Mandeville em relação ao mundo, analisasse as terminologias usadas pelo autor ao descrever todos os povos encontrados no Oriente.

\section{REFERÊNCIAS}

ACOSTA, Vladimir. Viajeros y maravillas. Tomo III. Monte Avila Editores Latinoamericana, 1992.

BOVERY, Alixe. Monstruos y grutescos en los manuscritos medievales. Madrid: TURNER, 2006.

CASTRO HERNÁNDEZ, Pablo. La imagen del monstruo en algunas representaciones xilográficas del Libro de las maravillas del mundo de John Mandeville. Revista Sans Soleil, no 7, 2005, pg.14-24.

CASTRO HERNÁNDEZ. El libro de viajes como enciclopedia: un catálogo de monstruos y maravillas en los viajes de sir John Mandeville. Revista Sans Soleil: estudios de la imagem, vol. 5, n.2, 2013, p.188-204.

CUENCA, Carmem Manuel. Elementos fantasticos en los libros de viajes de Juan Mandevilla. Atlantis, vol. VIII, nº s. 1-2, jun-nov. 1986 (21-35).

DEL PRIORI, Mary. Esquecidos por Deus:monstros no mundo europeu e lberoAmericano (séculos XIV-XVIII). São Paulo: Companhia das Letras, 2000.

FRANÇA, Susani Silveira Lemos. Introdução. In: Viagens de Jean de Mandeville. Bauru, SP: EDUSC, 2017.

HÖFERT, Almurt. Miracles, Marvels and Monsters in the Middle Ages. Living History Books: digital anthology with open access sources, 2016, p.1-25. Disponível em: https://www.livingbooksabouthistory.ch/uploads/media/pdf/en/miracles-marvels-andmonsters-in-the-middle-ages.pdf. Acesso em: 25/07/2019.

KAPPLER, Claude. Monstruos, demonios y maravillas a fines de la Edad Media. Madrid, españa: Ediciones Akal, 1986.

KIMBLE, George H. T. A Geografia na Idade Média. Londrina, PR; São Paulo, SP: EDUEL: Imprenta Oficial do Estado de São Paulo, 2005.

LE GOFF, Jacques. O maravilhoso e o quotidiano no Ocidente Medieval. Lisboa: Portugal; Edições 70, 1985.

LE GOFF, Jacques. O maravilhoso. In: LE GOFF, Jacques (Org.). Dicionário analítico do Ocidente Medieval. São Paulo: Editora Unesp, 2017, v.2, p. 120-138. 
MENDONÇA, Ana Teresa Pollo. O imaginário Antigo e Medieval. In: Por mares nunca dantes cartografados: a permanência do imaginário antigo e medieval na cartografia moderna dos descobrimentos marítimos ibéricos em África, Ásia e América através dos oceanos Atlânticos e Índico nos séculos XV e XVI. Dissertação (Mestrado em História), Programa de Pós-graduação em História Social e Cultural, do Departamento de História da PUC-Rio 2007. Disponível em: http://ivros01.livrosgratis.com.br/cp040423.pdf Acessado em: 05/09/2018.

MOSELEY, C. W. R. D. Introduction. In: The travels of Sir John Mandeville. Translated with an introduction by C. W. R. D. Moseley, Penguin Classics, 1986.

MOSELEY, Charles. The travels of Sir John Mandeville and the Moral Geography of the Medieval World. Portal, Vol. 12, n¹, January 2015.

OSORIO, Susana Morales; HOYOS, Sonia Fernández . El mediterráneo a través de la ficción: el extraño caso de sir John Mandeville. Anuario de Estudios medievales (AEM), 36/1, 2006, p.335-354.

QUESADA, Miguél Ángel Ladero. Mundo real y mundos imaginarios. John Mandeville. In: PORTELA, Feliciano Novoa; RUIZ TOLEDO, Fernando Javier Villalba (Org.). Viajes y viajeros en la Europa medieval. Lunwere Editores, 2007, pg. 55-74.

RUIZ DE TOLEDO, F. Javiel Villalba, PORTELA, Feliciano Portela. Los mitos medievales en la obra de John Mandeville. ISIMU: Revista sobre Oriente Próximo y Egipto en la Antigüedad 9 (2006): 37-57.

SCHNEIDER, Guilherme Jacinto. Guardiões do Éden: narrativas de encontros com criaturas maravilhosas na América Portuguesa - séculos XVI. 2015. Dissertação (Mestrado)- Universidade Federal Juiz de Fora, Juiz de Fora, 2015. Disponível em: http://www.ufff.br/ppghistoria/files/2015/08/Monstros-no-Para\%C3\%ADso-Guilherme-

Schneider.pdf. Acesso em: 28/06/2019.

TOVÁR, Joaquín Rubio. Monstruos y seres fantásticos en la literatura y pensamiento Medieval. In: Poder y seducción de la imagen românica. Aguilar de Campo, 2006.

VALENZUELA, Victoria Cirlot. La estética de lo monstruoso en la Edad Media. Revista de literatura medieval, № 2, 1990, p. 175-182.

VIAGENS DE JEAN DE MANDEVILLE. Bauru, SP: EDUSC, 2017. 